\title{
Composite Shaft Optimization Using Simulated Annealing, Part I: Natural Frequency
}

\author{
H. B. H. GUBRAN* and K. GUPTA ${ }^{\dagger}$ \\ Mechanical Engineering Department, Indian Institute of Technology, Delhi, Hauz-Khas, New Delhi-110016, India
}

\begin{abstract}
In this study a fiber-reinforced composite shaft design is optimized. The optimization procedure is carried out in two stages. First, the shaft natural frequency is maximized with the constraint imposed on the shaft buckling torque and torsional strength. In the second stage of optimization, shaft weight is minimized with the constraint imposed on the natural frequency obtained from the first stage, shaft buckling torque and torsional strength. Shafts of uniform layup and uniform wall thickness (UU), uniform fiber layup and variable wall thickness (UV), variable fiber layup and uniform wall thickness (VU) and variable fiber layup and variable wall thickness (VV) have been considered. The shaft is modelled as a simply supported Timoshenko beam in which shear deformation, rotary inertia and gyroscopic effects are included. Rayleigh-Ritz displacement are used for deriving the solution equation. A Simulated Annealing (SA) global optimization routine is used. Although this routine requires large number of function evaluations to find the optimum solution, it finds the global optimum with high probability even for ill conditioning functions with numerous local minima.
\end{abstract}

Keywords: Composite shafts; Optimization; Natural frequency; Shaft weight; Simulated Annealing

The utilization of composite materials in structural applications has grown considerably in recent years. The major advantage in using composite materials is their high strength-to-weight ratio. One of the major applications of composite materials is to composite drive shafts, where high strength-to-weight and stiffness-to-weight ratios are important. Composite drive shafts can be designed to have

Received 28 November 2000.

*E-mail: hason@mech.iitd.ernet.in

${ }^{\dagger}$ Corresponding author. E-mail: kgupta@mech.iitd.ernet.in greater unsupported shaft length than traditional metallic shafts carrying the same load.

The applications of numerical optimization techniques to the design of composite shafts has proved to be effective in reducing shaft weight. In spite of the availability of several optimization techniques, no single method yields satisfactory performance across the spectrum of engineering design problems. Calculus-based search techniques utilizing gradient information to guide the search work are designed for optimization problem with continuous variables. These methods are inadequate for problems with discrete/discrete-continuous variables, which appear due to practical considerations such as the availability of components in standard sizes, construction and manufacturing practices. Therefore, efficient techniques for solving problems with discrete-continuous variables are needed. Simulated Annealing (SA) is a search procedure based on Monte-Carlo method used in statistical mechanics studies of condensed system. Kirkpatrick et al. (1983) showed the analog between simulating the annealing of solids as proposed by Metropolis et al. (1983) and solving combinatorial optimization problems.

Optimization of composite drive shafts during past few years using traditional methods was carried by (Kraus, 1988; Bauchau, 1983; Darlow \& Creonte, 1995; Gubran, 1994; Gubran \& Gupta, 1996; and Wettergren, 1997). However in literature, there is no work on the optimization of composite drive shafts using nontraditional methods. In the present paper Simulated Annealing (SA) algorithm is used to optimize composite shaft of uniform/variable-fiber layup/wall thickness.

\section{ANALYSIS}

This paper deals with optimization of the natural frequency of balanced laminate composite shafts of uniform/variablefibre layup/wall thickness, i.e., UU, UV, VU, and VV cases. In axially variable fibre layup and (or) axially 
variable wall thickness, the axial symmetry about the shaft mid-span is assumed.

\section{Natural Frequency Analysis}

The shaft is modeled as a simply supported Timoshenko beam in which shear deformation, rotary inertia and gyroscopic effects have been included. Rayleigh-Ritz displacements are used for deriving the solution equation. Referring to Figure 1, the displacement field is described by the transverse displacements, $w$ and $v$ measured in the $z$ and $\mathrm{y}$ directions, the bending slopes $\alpha$ and $\beta$ in the $\mathrm{x}-\mathrm{z}$ and $\mathrm{x}-\mathrm{y}$ planes and $\varphi$ is the shaft twist angle. The quantities $\mathrm{w}, \mathrm{v}, \alpha, \beta$ and $\varphi$ are assumed to be time dependent and can be represented as

$$
\begin{gathered}
\mathrm{w}=\overline{\mathrm{w}} \mathrm{e}^{\mathrm{i} \Omega \mathrm{t}} \quad \mathrm{v}=\overline{\mathrm{v}} \mathrm{e}^{\mathrm{i} \Omega \mathrm{t}} \quad \alpha=\bar{\alpha} \mathrm{e}^{\mathrm{i} \Omega \mathrm{t}} \\
\beta=\bar{\beta} \mathrm{e}^{\mathrm{i} \Omega \mathrm{t}} \quad \varphi=\bar{\varphi} \mathrm{e}^{\mathrm{i} \Omega \mathrm{t}}
\end{gathered}
$$

where $\Omega$ is the whirl frequency.

The strain energy of the shaft at any stressed state is given by

$$
\mathrm{U}=\sum_{\mathrm{k}=1}^{\mathrm{n}} \mathrm{U}^{\mathrm{k}}=\frac{1}{2} \sum_{\mathrm{k}=1}^{\mathrm{n}} \int_{\mathrm{v}}\left[\sigma^{\mathrm{k}}\right]^{\mathrm{T}}\left\{\varepsilon^{\mathrm{k}}\right\} \mathrm{dv}
$$

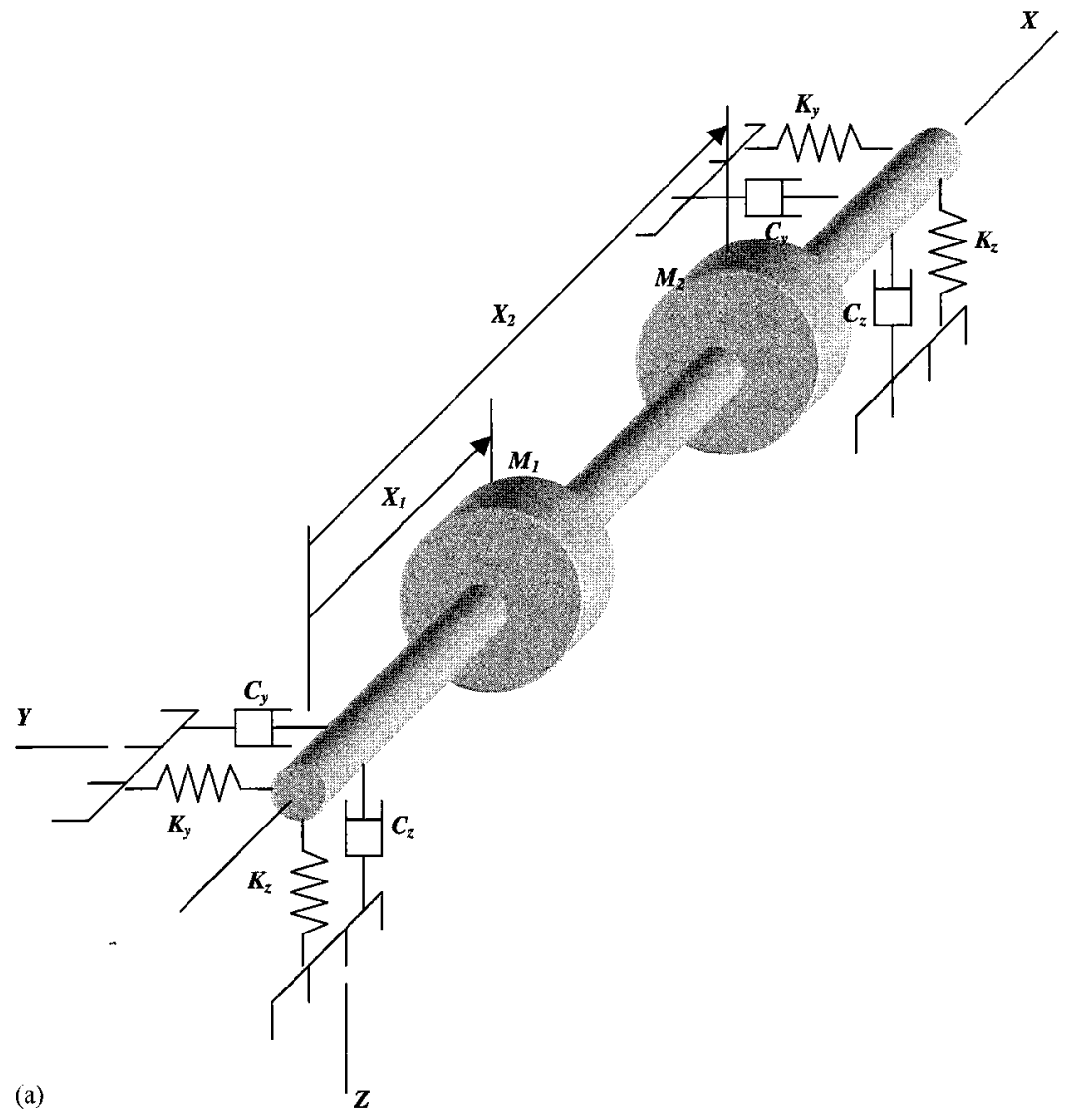

(b)
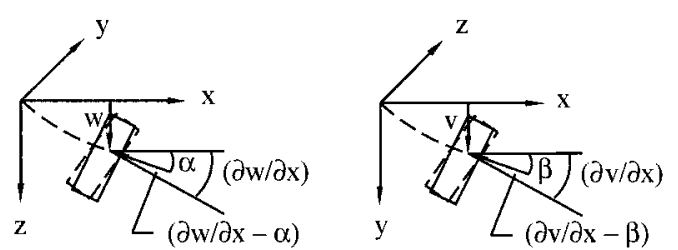

FIGURE 1 (a) Coordinate system of the rotor, (b) Displacement field in Cartesian coordinate. 
where the summation is taken over all the layers contained in the laminate, and

$$
\left[\sigma^{\mathrm{k}}\right]=\left\{\begin{array}{c}
\sigma_{\mathrm{x}} \\
\sigma_{\mathrm{y}} \\
\tau_{\mathrm{xy}}
\end{array}\right\}^{\mathrm{k}}=\left[\begin{array}{lll}
\overline{\mathrm{Q}}_{11} & \overline{\mathrm{Q}}_{12} & \overline{\mathrm{Q}}_{16} \\
\overline{\mathrm{Q}}_{12} & \overline{\mathrm{Q}}_{22} & \overline{\mathrm{Q}}_{26} \\
\overline{\mathrm{Q}}_{16} & \overline{\mathrm{Q}}_{26} & \overline{\mathrm{Q}}_{66}
\end{array}\right]^{\mathrm{k}}\left\{\begin{array}{c}
\varepsilon_{\mathrm{x}} \\
\varepsilon_{\mathrm{y}} \\
\varepsilon_{\mathrm{xy}}
\end{array}\right\}^{\mathrm{k}}
$$

where $\sigma_{\mathrm{x}}$ and $\sigma_{\mathrm{y}}$ are in-plane normal stresses and $\tau_{\mathrm{xy}}$ is the in-plane shear stress, $\varepsilon_{\mathrm{x}}$ and $\varepsilon_{\mathrm{y}}$ are the in-plane normal strains and $\varepsilon_{x y}$ is the in-plane shear strain. $\bar{Q}$ is the transformed stiffness matrix of the $k$ th layer. The strain energy including bending in two planes, shear deformation and torsion can be expressed as

$$
\begin{aligned}
\mathrm{U}=\frac{1}{2} \int_{0}^{\ell}[ & \mathrm{C}_{\mathrm{B}}\left\{\left(\frac{\partial \alpha}{\partial \mathrm{x}}\right)^{2}+\left(\frac{\partial \beta}{\partial \mathrm{x}}\right)^{2}\right\} \\
& +\mathrm{C}_{\mathrm{s}}\left\{\left(\frac{\partial \mathrm{w}}{\partial \mathrm{x}}-\alpha\right)^{2}+\left(\frac{\partial \nu}{\partial \mathrm{x}}-\beta\right)^{2}\right\} \\
& \left.+\mathrm{C}_{\mathrm{T}}\left(\frac{\partial \varphi}{\partial \mathrm{x}}\right)^{2}\right] \mathrm{dx}
\end{aligned}
$$

The bending stiffness coefficient is given by

$$
\mathrm{C}_{\mathrm{B}}=\frac{\pi}{4} \sum_{\mathrm{k}=1}^{\mathrm{n}} \overline{\mathrm{Q}}_{11}^{(\mathrm{k})}\left[\mathrm{R}_{0(\mathrm{k})}^{4}-\mathrm{R}_{\mathrm{i}(\mathrm{k})}^{4}\right]
$$

and the torsional stiffness coefficient is

$$
\mathrm{C}_{\mathrm{T}}=\frac{\pi}{2} \sum_{\mathrm{k}=1}^{\mathrm{n}} \overline{\mathrm{Q}}_{66}^{(\mathrm{k})}\left[\mathrm{R}_{0(\mathrm{k})}^{4}-\mathrm{R}_{\mathrm{i}(\mathrm{k})}^{4}\right]
$$

The shear stiffness coefficient is $\mathrm{C}_{\mathrm{s}}=\mathrm{KAG}_{\mathrm{xy}}$, where $\mathrm{K}$ is the shear correction factor given by

$$
\mathrm{K}=\frac{1}{2}\left(1-\frac{\nu_{\mathrm{xy}} \mathrm{G}_{\mathrm{xy}}}{\mathrm{E}_{\mathrm{y}}}\right)^{-1}
$$

The total kinetic energy is the sum of the kinetic energies of the shaft and of the disks mounted on it. This can be expressed as

$$
\begin{aligned}
\mathrm{T}=\frac{1}{2} \int_{0}^{\ell} & {\left[\rho \mathrm{A}\left(\dot{\mathrm{w}}^{2}+\dot{\mathrm{v}}^{2}\right) \mathrm{dx}+\rho \mathrm{I}\left(\dot{\alpha}^{2}+\dot{\beta}^{2}\right) \mathrm{dx}\right.} \\
& \left.+\rho \mathrm{I}_{\mathrm{p}} \dot{\varphi}^{2}+2 \rho \mathrm{I}_{\mathrm{p}} \omega \dot{\alpha} \beta\right] \mathrm{dx} \\
& +\frac{1}{2} \sum_{\mathrm{i}=1}^{\mathrm{ND}}\left[\mathrm{M}_{\mathrm{Di}}\left(\dot{\mathrm{w}}\left(\mathrm{x}_{\mathrm{i}}\right)^{2}+\dot{\mathrm{v}}\left(\mathrm{x}_{\mathrm{i}}\right)^{2}\right)\right. \\
& +\mathrm{I}_{\mathrm{D}_{\mathrm{Ti}}}\left(\dot{\alpha}\left(\mathrm{x}_{\mathrm{i}}\right)^{2}+\dot{\beta}\left(\mathrm{x}_{\mathrm{i}}\right)^{2}\right)+\mathrm{I}_{\mathrm{Dpi}} \dot{\varphi}^{2} \\
& \left.+2 \mathrm{I}_{\mathrm{Dpi}} \omega \dot{\alpha}\left(\mathrm{x}_{\mathrm{i}}\right) \beta\left(\mathrm{x}_{\mathrm{i}}\right)\right]
\end{aligned}
$$

Here $\rho$ is the mass density of the shaft material, A and I are area and second area moment of shaft cross-section. $\mathrm{M}_{\mathrm{Di}}$,
$\mathrm{I}_{\mathrm{DTi}}$ and $\mathrm{I}_{\mathrm{DPi}}$ are mass, lateral and polar mass moments of inertia of the ith disc respectively. The rotational angular speed of the shaft is $\omega$.

In the design of variable wall thickness and (or) variable fibre layup, the shaft is divided into $n$ number of segments along the axial length and the axial symmetry about the shaft mid-span is assumed. Rayleigh-Ritz procedure presented for the case of uniform shaft is used. The integration is carried over each segment of uniform thickness, the local stiffness and mass matrices are calculated for different segments and put into the global stiffness and mass matrices.

\section{Solution Equations}

The series solution functions are assumed for $\mathrm{w}, \mathrm{v}, \alpha, \beta$, and $\varphi$ in the form

$$
\begin{aligned}
& \overline{\mathrm{w}}(\mathrm{x})=\sum_{\mathrm{n}=1}^{\mathrm{K}} \mathrm{W}_{\mathrm{n}} \sin \frac{\mathrm{n} \pi \mathrm{x}}{\ell}, \quad \overline{\mathrm{v}}(\mathrm{x})=\sum_{\mathrm{n}=1}^{\mathrm{K}} \mathrm{V}_{\mathrm{n}} \sin \frac{\mathrm{n} \pi \mathrm{x}}{\ell} \\
& \bar{\alpha}(\mathrm{x})=\sum_{\mathrm{n}=1}^{\mathrm{K}} \mathrm{A}_{\mathrm{n}} \cos \frac{\mathrm{n} \pi \mathrm{x}}{\ell}, \bar{\beta}(\mathrm{x})=\sum_{\mathrm{n}=1}^{\mathrm{K}} \mathrm{B}_{\mathrm{n}} \cos \frac{\mathrm{n} \pi \mathrm{x}}{\ell} \\
& \bar{\varphi}(\mathrm{x})=\sum_{\mathrm{n}=1}^{\mathrm{K}} \Psi_{\mathrm{n}} \cos \frac{\mathrm{n} \pi \mathrm{x}}{\ell}
\end{aligned}
$$

where $\mathrm{K}$ is total number of terms in the series solutions. The above functions satisfy geometric boundary conditions at $\mathrm{x}=0$ and $\mathrm{x}=l$. The Lagrangian $\mathrm{L}$ is set up from strain and kinetic energies and made stationary with respect to the solution coefficients, i.e.,

$$
\begin{aligned}
\frac{\partial \mathbf{L}}{\partial \mathbf{W}_{\mathrm{n}}} & =0, \quad \frac{\partial \mathrm{L}}{\partial \mathbf{V}_{\mathrm{n}}}=0, \quad \frac{\partial \mathrm{L}}{\partial \mathrm{A}_{\mathrm{n}}}=0, \\
\frac{\partial \mathrm{L}}{\partial \mathbf{B}_{\mathrm{n}}} & =0, \quad \frac{\partial \mathrm{L}}{\partial \Psi_{\mathrm{n}}}=0
\end{aligned}
$$

The time dependence cancels out in all the terms and a set of $5 \mathrm{~K}$ simultaneous algebraic equations in the form of a quadratic eigenvalue problem is obtained as

$$
\left[-\Omega^{2}[\mathrm{M}]+\mathrm{i} \Omega[\mathrm{D}]+[\mathrm{K}]\right\rfloor\{\mathrm{X}\}=\{0\}
$$

Here the matrix [D] involves the contribution due to gyroscopic effect and is dependent on rotational speed. The vector ' $\mathrm{X}$ ' is given by

$$
\begin{aligned}
\{\mathrm{X}\}= & {\left[\mathrm{W}_{1}, \mathrm{~W}_{2}, \ldots, \mathrm{W}_{n} \quad \mathrm{~V}_{1}, \mathrm{~V}_{2}, \ldots, \mathrm{V}_{\mathrm{n}}\right.} \\
& \left.\mathrm{A}_{1}, \mathrm{~A}_{2}, \ldots, \mathrm{A}_{n} \quad \mathrm{~B}_{1}, \mathrm{~B}_{2}, \ldots, \mathrm{B}_{n} \quad \Psi_{1}, \Psi_{2}, \ldots, \Psi_{\mathrm{n}}\right]^{\mathrm{T}}
\end{aligned}
$$




\section{SIMULATED ANNEALING ALGORITHM}

Simulated annealing basics are in thermodynamics where one studies the system thermal energy. A description of the cooling of molten metal motivates this algorithm. At high temperature, the atoms in the molten metal can move freely with respect to each other but as the temperature is reduced, the movement of the atoms gets restricted. The atoms start to get ordered and finally form crystals having the minimum possible energy. However, the formation of the crystal mostly depends on the cooling rate. If the temperature is reduced at a very fast rate, the crystalline state may not be achieved at all, instead the system may end up in a polycrystalline state. In the analogy, the different states of the substance correspond to the different feasible solutions of the combinatorial optimization problem, and the energy of the system corresponds to the function to be minimized.

In simulated annealing, the problem starts at some initial solution and a series of moves (changes in the values of design variables) are made according to a user-defined annealing schedule until either the optimal solution is attained or the problem becomes frozen at a local optimum for which it cannot improve. To avoid freezing at a local optimum, the algorithm moves slowly (with respect to the value of the objective) through the solution space. This controlled improvement of the objective value is accomplished by accepting non-improving moves with a certain probability (based on the resulting change in the objective function value and the current temperature) which decreases as the algorithm progresses. The cooling phenomenon is simulated by controlling a temperature-like parameter introduced with the concept of the Boltzmann probability distribution. According to the Boltzmann probability distribution, a system in thermal equilibrium at a temperature $\mathrm{T}$ has its energy distributed probabilistically according to $p(E)=e^{(-E / K T)}$, where $K$ is the Boltzmann constant. This expression suggests that a system at a high temperature has almost uniform probability of being at any energy state, but at low temperature it has a small probability of being at a high energy state. Therefore, by controlling the temperature $\mathrm{T}$ and assuming that the search process follows the Boltzmann probability distribution, the convergence of an algorithm can be controlled. For any instant $t$ at point $\mathrm{x}(\mathrm{t})$, the value of the function is $\mathrm{E}(\mathrm{t})=\mathrm{f}(\mathrm{x}(\mathrm{t}))$. Using Metropolis algorithm, the probability of the next point at $x(t+1)$ depends on the difference in the function value at these points i.e., $\Delta \mathrm{E}=\mathrm{E}(\mathrm{t}+1)-\mathrm{E}(\mathrm{t})$, and is calculated using the Boltzmann probability distribution $\mathrm{P}(\mathrm{E}(\mathrm{t}+1))=\min [1, \exp (-\Delta \mathrm{E} / \mathrm{kT})]$. For $\Delta \mathrm{E}<0$, the probability is one and the new point is accepted. If $\Delta \mathrm{E}>0$ i.e., $\mathrm{f}(\mathrm{x}(\mathrm{t}+\mathrm{l}))>\mathrm{f}(\mathrm{x}(\mathrm{t}))$, the point is still accepted with some finite probability. This is not the same in all solutions and depends on relative magnitudes of $\Delta \mathrm{E}$ and $\mathrm{T}$.
The general procedure for implementing a simulated annealing algorithm (as shown in Figure 2), is as follows,

Step 1 Select an initial temperature $\mathrm{T}$, and initial solution $X_{0}$. Let $f_{0}=f\left(X_{0}\right)$ denote the corresponding objective value. Set $\mathrm{i}=0$ and go to Step 2 .

Step 2 Set $\mathrm{i}=\mathrm{i}+1$ and generate new solution, $\left(\mathrm{X}_{\mathrm{i}}{ }^{\prime}=\mathrm{X}_{\mathrm{i}}+\mathrm{r} \cdot \mathrm{V}_{\mathrm{i}}\right)$ where, $\mathrm{r}$ is random number and $V_{i}$ is step length. Evaluate $f_{i}^{\prime}=f\left(X_{i}^{\prime}\right)$.

Step 3 If $\mathrm{f}_{\mathrm{i}}^{\prime}<\mathrm{f}_{\mathrm{i}-1}$, go to Step 5 , else accept $\mathrm{f}_{\mathrm{i}}$ as the new solution with the probability $\mathrm{e}^{(-\Delta \mathrm{E} / \mathrm{T})}$, where $\Delta \mathrm{E}=\mathrm{f}_{\mathrm{i}}^{\prime}-\mathrm{f}_{\mathrm{i}-1}$ and go to Step 4 .

Step 4 If $\mathrm{f}_{\mathrm{i}}$ was rejected in Step 3, set $\mathrm{f}_{\mathrm{i}}^{\prime}=\mathrm{f}_{\mathrm{i}-\mathrm{l}}$. Go to Step 5.

Step 5 If satisfied with the current objective value, $\mathrm{f}_{\mathrm{i}}$, stop. Otherwise, adjust the temperature $\left(\mathrm{T}^{\prime}=\mathrm{T} \cdot \mathrm{r}_{\mathrm{T}}\right)$ where $r_{T}$ is temperature reduction rate and go to Step 2.

The important parameters which govern the successful working of the simulated annealing procedure are the

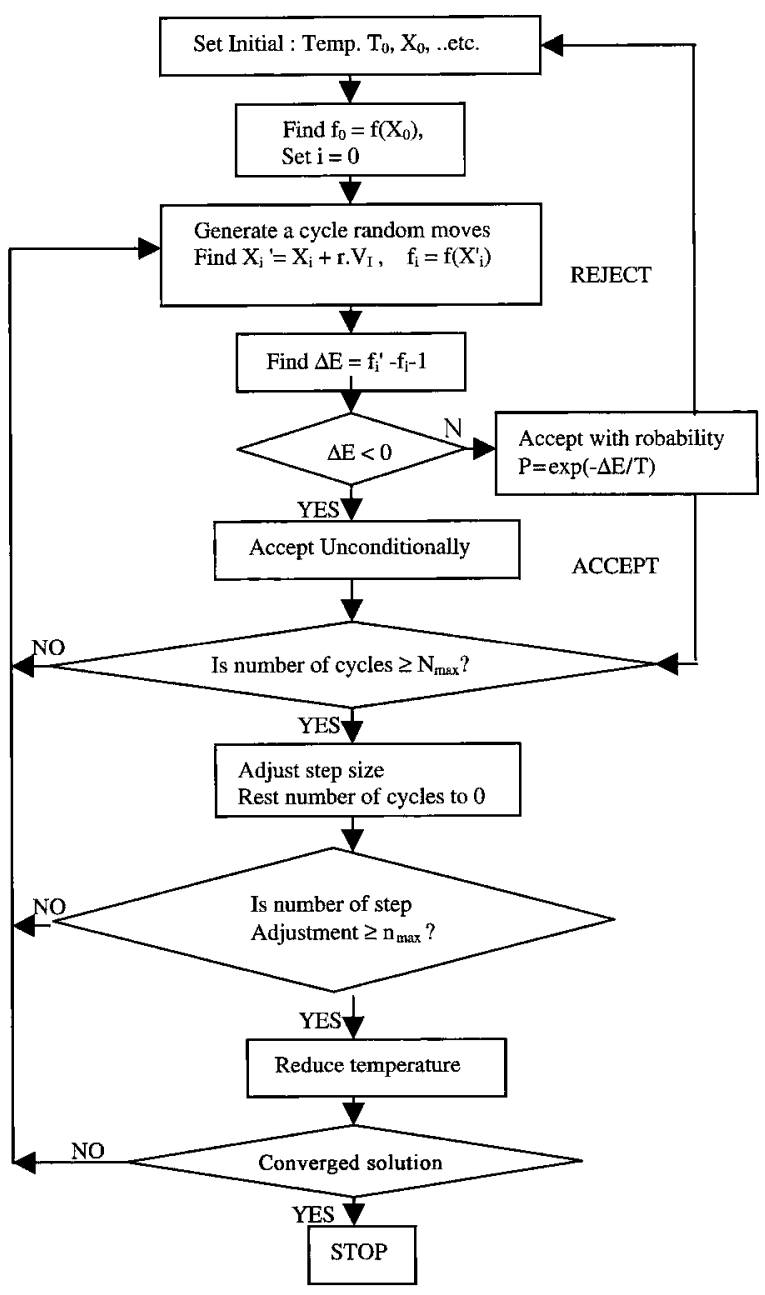

FIGURE 2 Flowchart for simulated annealing algorithm. 
initial temperature $T$, temperature reduction rate $\mathbf{r}_{T}$ and the number of iterations $n$ performed at a particular temperature. If a large initial temperature $\mathrm{T}$ is chosen, it requires a large number of iterations for convergence. On the other hand, if a small initial temperature $T$ is chosen, the search is not adequate to thoroughly investigate the search space before converging to the true optimum.

\section{PROBLEM DESCRIPTION AND OPTIMIZATION}

The important problems in the design of high speed rotating composite shaft of significant span are the lateral stability and critical speed placement. Generally, with light weight (Graphite/Epoxy) material, it is relatively easy to meet the torsional strength. The optimal design of the composite shafts is put as a nonlinear mathematical programming problem. The objective function here is to have a shaft with minimum weight and satisfy design requirements of buckling torque, torsional strength and critical speed placement.

The design variables are the orientation of different ply angles, the thickness of each ply and the stacking sequence of different ply angles. Ply orientation can vary over a wide range. However limiting this variation within a considerable range $\left(0^{\circ}\right.$ to $\left.45^{\circ}\right)$, helps in increasing the robustness of the procedures used.

The optimization procedure consists of two steps. In the first step, maximization of shaft natural frequency was carried out under the constraints of buckling torque and shear strength requirements. This procedure is defined as natural frequency maximization. In the second procedure, shaft weight is minimized under the constraints of critical speed obtained from the first procedure, the buckling torque and shear strength requirements. Mathematically, the formulation can be written as:

Step 1 (Natural Frequency Maximization)

$$
\text { Maximize } \ddot{f}_{s 1}
$$

Subjected to:

$$
\begin{gathered}
T_{B u c} \geq \text { F.O.S. } \times T \\
\tau_{U l t} \geq 1.5 \times \tau=1.5 \times \frac{T}{2 \pi r_{m}^{2} t} \\
\mathrm{r}_{\text {inner }} \leq \mathrm{R}
\end{gathered}
$$

$0^{\circ} \leq \theta \leq 45^{\circ}$ (to include balanced laminate conditions).

Equation [10] represents maximization of the natural frequency while Eq. [11] represents the buckling torque constraint which implies that final design of the shaft should have a buckling torque capacity which is greater or equal to the transmitted torque multiplied by factor of safety (F.O.S) taken here as 2.25. Equation [12] represents the constraint on the shear stress induced in the shaft. However, Eq. [13] represents geometrical constraint imposed on shaft inner radius.

Step 2 (Weight Minimization)

$$
\text { minimize } W=2 \pi r_{m} t \rho l
$$

Subjected to:

$$
\begin{gathered}
f=f_{s 1} \\
T_{B u c} \geq \text { F.O.S. } \times T \\
\tau_{U l t} \geq 1.5 \times \tau=1.5 \times \frac{T}{2 \pi r_{m}^{2} t} \\
\mathrm{r}_{\text {inner }} \leq \mathrm{R}
\end{gathered}
$$

$0^{\circ} \leq \theta \leq 45^{\circ}$ (to include balanced laminate condition).

Here $f_{\mathrm{s} 1}$ is the maximized natural frequency calculated from Step 1. It is to be noted that if the natural frequency calculated from Eq. [15] is close to one of the shaft critical speeds, then a margin of $20 \%$ of shaft operating speed below or above the operating speed has to be considered. In this case, the constraint of Eq. [15] is modified as

$$
\begin{aligned}
& \mathrm{f}_{1} \leq 0.8 \mathrm{~N} \\
& \mathrm{f}_{2} \geq 1.2 \mathrm{~N}
\end{aligned}
$$

where $\mathrm{N}$ is the shaft operating speed. Equation [15a] ensures that the first natural frequency is $20 \%$ below the operating speed and Eq. [15b] ensures that the second natural frequency is $20 \%$ above the operating speed.

\section{RESULTS AND DISCUSSION}

In this study two shafts of different length were taken. The first shaft is $1 \mathrm{~m}$ long and the inner radius is limited to a maximum value $R$ of $0.05 \mathrm{~m}$. The second shaft is $6 \mathrm{~m}$ long and the inner radius is limited to a maximum value of $0.06 \mathrm{~m}$. By convention, ply angles are considered to be between $0^{\circ}$ and $90^{\circ}$. As ply angle increases, the axial modulus of the shaft, which governs the bending stiffness, decreases. The upper limit on ply angle of $45^{\circ}$ is considered here. The material properties of both shafts are same as that given in Table I. To achieve a closed loop analysis, the optimization subroutines were linked with the main 
TABLE I Shaft material properties

\begin{tabular}{ll}
\hline Major Elastic Modulus, $\mathrm{E}_{1}$ (Gpa) & 130 \\
Minor Elastic Modulus, $\mathrm{E}_{2}$ (Gpa) & 10 \\
Major Poisson ratio, $\nu_{12}$ & 0.25 \\
Shear Moduli, $\mathrm{G}_{12}=\mathrm{G}_{13}(\mathrm{Gpa})$ & 7 \\
Density $\rho, \mathrm{kg} / \mathrm{m}^{3}$ & 1500 \\
\hline
\end{tabular}

subroutines which calculate natural frequencies, torsional strength and buckling load. As shown in Figure 3, the optimization process begins by initialization with some starting values for different design parameters in the optimization subroutine. Accordingly the shaft model is constructed in the main subroutine and natural frequencies, torsional strength and buckling torque are calculated. These are transferred again to the optimization subroutine and checked for convergence. If the design is not feasible or convergence criteria is not achieved, the optimization algorithm searches for a feasible design point and new model is created and the process is repeated till the convergence is achieved.

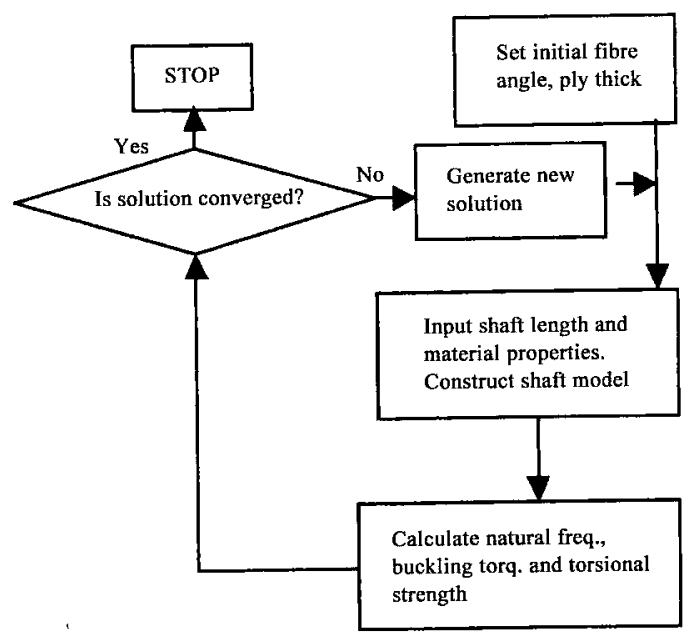

FIGURE 3 Design and optimization procedure.
To have a realistic value of torque $T$, reference has been made to an earlier study by Gubran and Gupta (1996) on helicopter tail rotor shaft transmitting $400 \mathrm{kw}$ at 4500 RPM. Assuming a factor of safety of 2.25 , the transmitting torque works out to $1910 \mathrm{Nm}$.

In this study, the improvement in the dynamic performance of two composite shafts of different lengths is studied. Different optimized design alternatives of uniform/ variable fiber layup/wall thickness have been considered. The convergence and sensitivity to different starting values on the performance of simulated annealing algorithms were tested for uniform fibre layup and wall thickness shafts.

\section{Optimization of Uniform Fiber Layup/Uniform Wall Thickness (UU) Shaft}

Analysis has been carried out on two shafts of $1 \mathrm{~m}$ and $6 \mathrm{~m}$ length. For each shaft, the two phases of optimization described earlier are applied. The natural frequency of the shaft was maximized in the first phase of the design where the constraints were imposed on the buckling torque and torsional strength. In the next phase, optimization is sought to minimize the shaft weight with the constraints on the natural frequency and buckling torque. Observations made from the results show that, reducing shaft weight (i.e., shaft wall thickness) had minimum effect on the natural frequency. The torsional strength in every case was lower than or equal to the ultimate torsional strength of the shaft. Results presented in Table II show that the optimal design parameters (i.e., ply angles) obtained for different starting points are almost the same. However ply thickness are different for different starting ply angles. This can be explained as follows. For the case of $1 \mathrm{~m}$ length the optimized ply angles for the prescribed constraints are found to be same (between $10.5^{\circ}$ to $10.8^{\circ}$ ). This can be considered simply a shaft with single ply angle, therefore individual ply thickness has no effect in this case. The ruling factor in this case will be the total thickness obtained for different starting values as this will define shaft mean radius. However, it is clear from the results presented in

TABLE II Effect of starting values on the performance of SA algorithms for uniform fiber layup and uniform wall thickness shafts $(\mathrm{UU})\left(\mathrm{r}_{\mathrm{T}}=0.2\right.$, $\left.\mathrm{T}_{0}=100\right)$

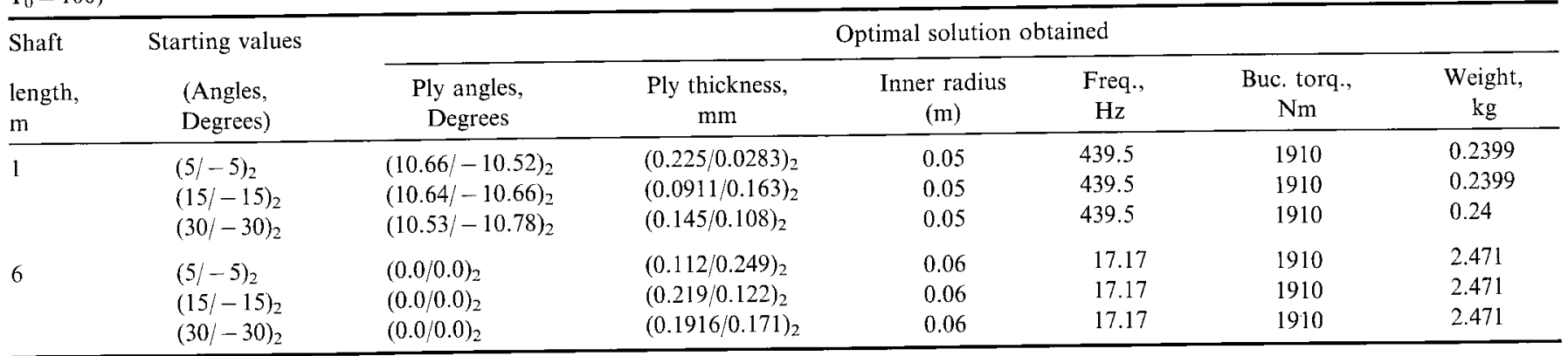


Table II, that for different starting values the total weight of the shaft is same. This implies that the total thickness is kept the same for different cases.

To check the sensitivity of the optimized results, three different starting values (distributed along the solution space) have been taken. Optimized results obtained for different starting solutions are almost the same for both shafts. This is clear from the exact matching of the values of the buckling torque and natural frequency obtained for different starting solutions for both shafts. Optimal ply angles obtained for different starting values for both shafts are same.

\section{Optimization of Uniform Fiber Layup/Variable Wall Thickness (UV) Shaft}

In variable wall thickness shaft, the shaft is divided into five segments and the axial symmetry about the mid-plane is assumed. The number of plies at each section are kept as 4, however ply thicknesses are allowed to vary. Analysis of uniform layup variable wall thickness shafts of $1 \mathrm{~m}$ and $6 \mathrm{~m}$ are presented in Table III. Results show that, for the $1 \mathrm{~m}$ long variable wall thickness shaft, the natural frequency can go up to $485 \mathrm{~Hz}$, which is higher by about $10 \%$ compared to that of the uniform wall thickness shaft for the same buckling torque constraint. There is also a reduction in the shaft weight by about $30 \%$ (i.e., from $0.239 \mathrm{~kg}$ to $0.167 \mathrm{~kg}$ ). Results for the $6 \mathrm{~m}$ long variable wall thickness shaft show an increase in the natural frequency by about $0.8 \%$ and a reduction in the shaft weight by about $21 \%$ (i.e., from $2.471 \mathrm{~kg}$ to $1.962 \mathrm{~kg}$ ). Results show that the optimally designed shafts are having different thickness at different locations. The middle Section (3) as obtained from both shafts is having maximum thickness. This can be explained as follows. For simply supported shaft, the deflection (for first mode) is maximum at the middle section. Providing maximum thickness at this section leads to an increase in the shaft stiffness at this section and therefore a reduction in the shaft maximum deflection. This leads to an increase in the shaft first natural frequency. Darlow and Creonte (1995) observed similar behaviour for torsional buckling torque. However, in the present study the buckling torque is kept the same for uniform and variable wall thickness shafts.

\section{Optimization of Variable Fiber Layup/Uniform Wall Thickness (VU) Shaft}

Another case considered for optimization is variable layup and uniform wall thickness in which the shaft is allowed to have different ply angles at different axial position along the shaft axial length. Five sections are assumed along the shaft length and the axial symmetry about the mid-plane is assumed. The analysis has been performed for the same shafts discussed in previous sections, i.e., shafts with $1 \mathrm{~m}$ and $6 \mathrm{~m}$ lengths. Results are presented in Table IV. For $1 \mathrm{~m}$ long shaft, optimized results show an increase in the natural frequency by about $9.3 \%$ compared to that of $\mathrm{UU}$, which is slightly less than that obtained by varying shaft wall thickness keeping same layup throughout the shaft axial length, i.e., UV. Results also show that there is no significant gains in reducing the shaft weight, which is about $5 \%$ (i.e., from $0.239 \mathrm{~kg}$ to $0.227 \mathrm{~kg}$ ) less than that of uniform layup/ uniform wall thickness shaft. Results for $6 \mathrm{~m}$ long shaft of the variable layup uniform wall thickness are almost the same as that of the uniform layup/uniform wall thickness shaft. The explanation for the above results is as follows. For $1 \mathrm{~m}$ long shaft, first phase of optimization, i.e., maximization of the natural frequency was performed successfully. However, the second phase, i.e., minimization of shaft weight, which is mainly achieved by manipulating thickness of different plies, is difficult to achieve due to constraint of having uniform wall thickness. Also the constraint of having uniform thickness, makes the end sections of the shaft (i.e., 1 and 5) almost redundant. This is clear from the higher ply angle values obtained. In fact, increasing the first natural frequency for the present case of simply supported shaft requires decreasing the maximum deflection of the shaft which is normally achieved by increasing the thickness of the shaft at middle section. Thickness of the shaft at end segments at which shaft deflection is minimum can be reduced without much

TABLE III Optimized results for uniform fiber layup and variable wall thickness (UV) shafts $\left(\mathrm{r}_{\mathrm{T}}=0.2 \mathrm{~T}_{0}=100\right)$

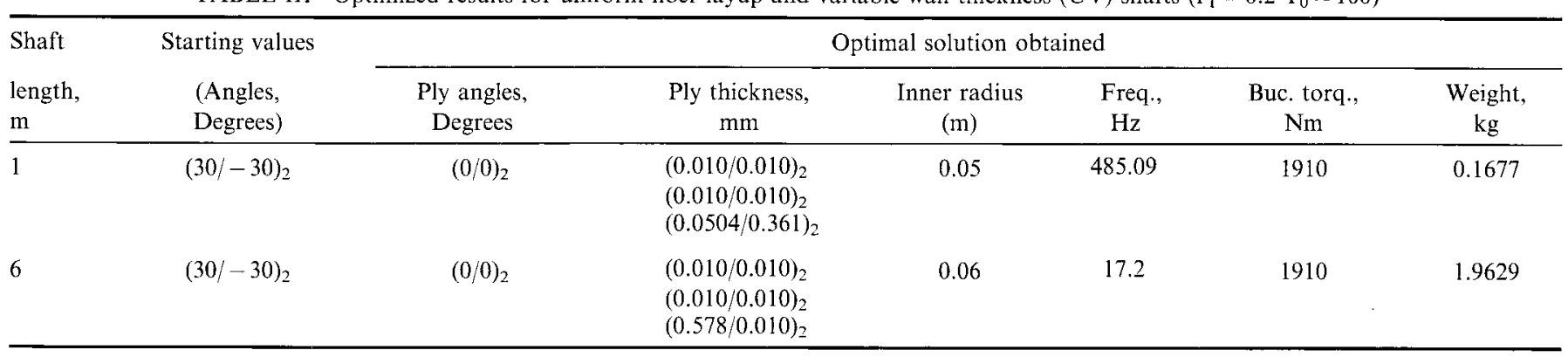


TABLE IV Optimized results for variable fiber layup uniform thickness (VU) shafts $\left(\mathrm{r}_{\mathrm{T}}=0.2 \mathrm{~T}_{0}=100\right)$

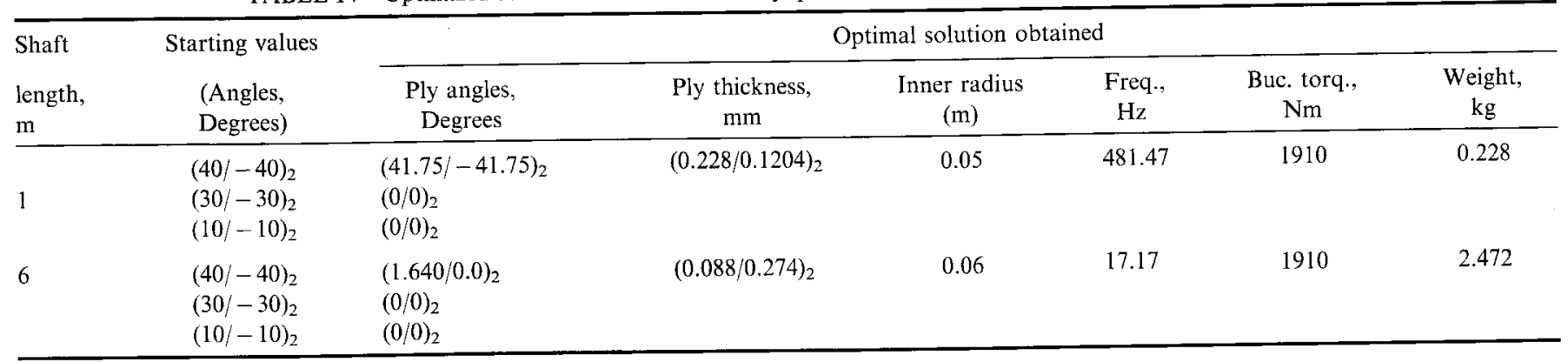

TABLE V Optimized results for variable fiber layup variable wall thickness (VV) shafts $\left(\mathrm{r}_{\mathrm{T}}=0.2 \mathrm{~T}_{0}=100\right)$

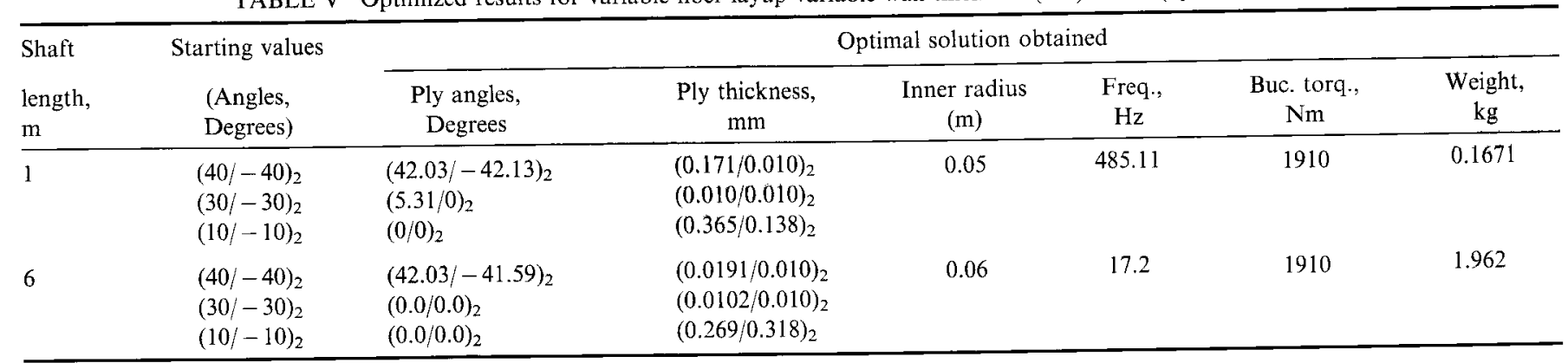

effecting the performance of the shaft, however keeping in mind the torsional strength requirement. Reducing shaft thickness at the end segments leads to a reduction in the total shaft weight which is not possible in the present VU case.

\section{Optimization of Variable Fiber Layup/Variable Wall Thickness (VV) Shaft}

In further step of optimization, the constraint imposed either on shaft layup or shaft thickness along different axial position of the shaft length are relaxed. In this, a variable fiber layup and variable wall thickness shaft optimization is carried. The two different shaft lengths, i.e., $1 \mathrm{~m}$ and $6 \mathrm{~m}$ have been analyzed. Optimized results presented in Table V are similar to that presented in Table III for the UV case. This clearly indicates that the improvement achieved in VV case is primarily due to variable wall thickness and not because of variable fiber layup. Results also show that, the middle section of both shafts have high stiffness. This is clear from $0^{\circ}$ ply angles having maximum thickness assigned for mid-section obtained in the optimized result leading to higher stiffness at the section and thereby increasing the shaft natural frequency.

\section{CONCLUSION}

In this study, Simulated Annealing algorithm is used for shaft optimization. In the optimization procedure, the shaft weight is minimized while the shaft natural frequencies are either maximized or properly placed in respect to operating speed. Constraints are imposed on the torsional buckling torque and torsional strength. Shaft individual ply angles, their stacking sequences and thicknesses along the axial length are kept as design variables, which have been optimized. Different design alternatives (UU, UV, VU, and VV) have been considered. Results obtained clearly show a significant improvement in the dynamic performance of the shaft by extending the design of uniform fiber ply angle and uniform wall thickness (UU) to a variable fiber ply angle and variable wall thickness (VV) case. Results also show that for simply supported shaft of maximum first natural frequency, the shaft stiffness has to be maximum at the middle segments of the shaft. This has been obtained here by placing ply angles of lower angles and maximum thickness at the middle segments of the shaft. Results also clearly show that the optimized results obtained by using Simulated Annealing algorithm are independent of the starting values as in the case of traditional methods of optimization. Results show that UV and VV cases provide 
the most effective and optimum design as compared to the $\tau_{\mathrm{x} \theta}, \varepsilon_{\mathrm{x} \theta}$ other cases.

\section{NOMENCLATURE}

$\begin{array}{ll}A & \text { Cross-sectional area of the shaft } \\ \mathrm{A}_{\mathrm{ij}} & \text { Elements in the extensional stiffness matrix A } \\ & \text { of the laminate }\end{array}$

$\mathrm{C}_{\mathrm{B}}, \mathrm{C}_{\mathrm{T}}, \mathrm{C}_{\mathrm{BT}}$ Bending, torsional, and bending-twisting stiffness coefficients

$\begin{array}{ll}\mathrm{G}_{\mathrm{xy}} & \text { Shear modulus } \\ \mathrm{I} & \begin{array}{l}\text { Second area moment of shaft cross- } \\ \text { section }\end{array}\end{array}$

$\mathrm{I}_{\mathrm{Dti}}, \mathrm{I}_{\mathrm{DPi}} \quad$ Lateral and polar mass moments of inertia of ith disk respectively

$l \quad$ Shaft length, $\mathrm{m}$

$[\mathrm{M}],[\mathrm{K}],[\mathrm{G}]$ Shaft mass, stiffness and gyroscopic matrices

$\mathrm{M}_{\mathrm{Di}} \quad$ Mass of ith disk

$Q_{i j}^{k}$

Elements in the stiffness matrix of the $\mathrm{kth}$ ply

$r_{m}$

$t_{i}, t$

$\mathrm{U}, \mathrm{T}$

$\mathrm{w}, \mathrm{v}$

$\{\mathrm{X}\}$

$Z_{k}$

$\alpha, \beta$

$\nu$

$\varphi$

$\varepsilon_{\mathrm{xx}}, \varepsilon_{\theta \theta}$ $\sigma_{\mathrm{xx}}, \sigma_{\theta \theta}$

$\Psi, \phi$

$\Omega$

$\omega$

$\rho$

Subscript

“,"

\section{Superscript}

“." denotes differentiation with respect to time.

Shear stress and strain in the lamina in $\mathrm{x}-\theta$ plane

Normal stresses in the lamina in $\mathrm{x}$ and $\theta$ directions

The bending and rotational slopes respectively

Whirl frequency

Shaft rotational speed of the shaft

Shaft material density, $\mathrm{kg} / \mathrm{m}^{3}$

denotes differentiation with respect to $\mathrm{x}$ or $\theta$.

\section{REFERENCES}

Bauchau, O. A. (1983) Optimal design of high speed rotating graphite/ epoxy shafts, Joumal of Composite Materials, 17, 170-181.

Darlow, M. S. and Creonte, J. (1995) Optimal design of composite helicopter power transmission shafts with axially varying fibre layup, Journal of American Helicopter Society, 40(2), 50-60.

Gubran, H. B. H. (1994) Optimum design of a helicopter tail rotor made of composite material, Masters Thesis, Mechanical Engineering Department IIT, Delhi, India.

Gubran, H. B. H. and Gupta, K. (1996) Optimal design of a helicopter tail rotor made of composite materials, CAD, CAM Automation, Robotics and Factories of future (INCARF 96 Proceedings), India, pp. 635-645.

Kirkpatrick, S., Gelatt, C. D. and Vecchi, M. P. (1983) Optimization by simulated annealing, Science, 220, 671-680.

Metropolis, N., Rosenbluth, A. W., Rosenbluth, M. N. and Teller, A. H. (1953) Education of state calculation by fast computing machines, Journal of Chem. Phys, 21, 1087-1092.

Wettergren, H. L. (1997) Influence of imperfection of a rotating composite shaft, Journal of Sound and Vibration, 204(1), 99-116.

Rao, S. S. (1998) Engineering Optimization, Theory and Practice. Third edition, New York. 

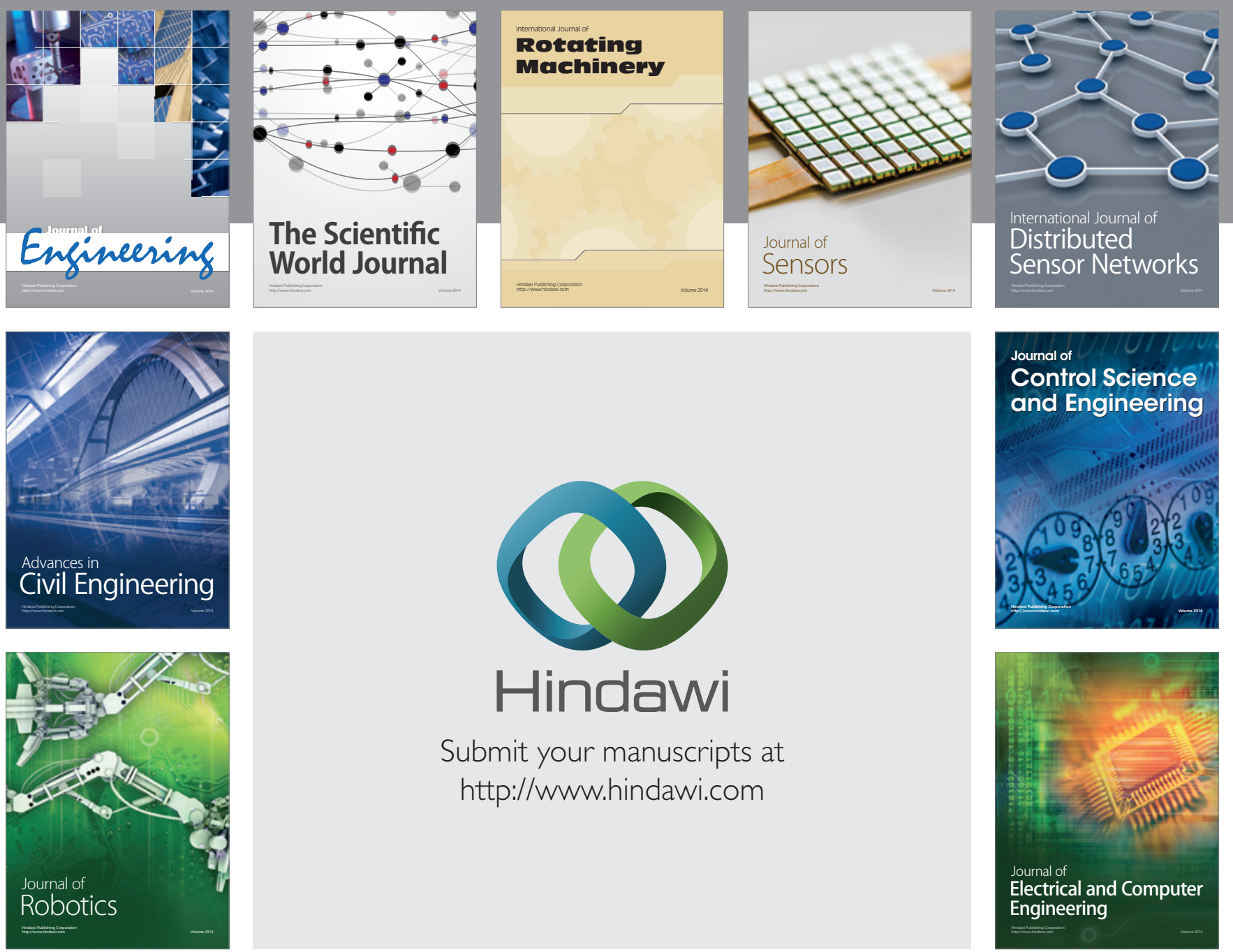

Submit your manuscripts at

http://www.hindawi.com
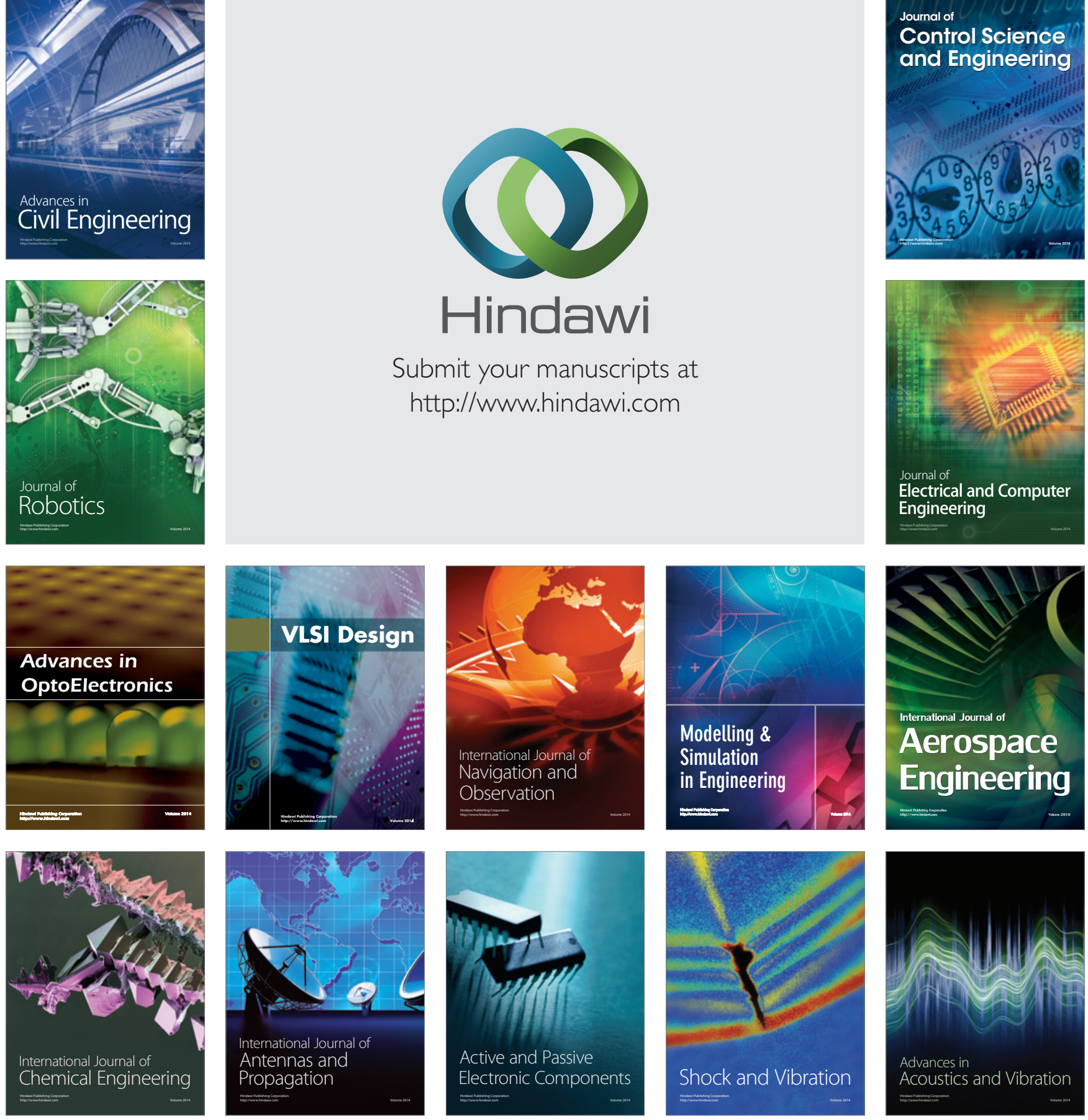